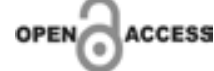

ACCESS

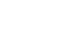

RESUMO DE ARTIGO

\section{Melanoma Nodular Amelanótico}

\author{
Nodular Melanoma Amelanotic
}

Thadeu Santos Silva ${ }^{1 *}$, Luciana Rebouças de Araujo ${ }^{2}$,
Gustavo Baptista de Almeida Faro ${ }^{1}$, Geise Rezende Paiva

1 Ambulatório do Serviço de Dermatologia do Hospital Universitário Professor Edgard Santos, Universidade Federal da Bahia; ${ }^{2}$ Ambulatório do Serviço de Dermatologia do Hospital Santa Izabel; ${ }^{3}$ Laboratório de Anatomia Patológica do Hospital Santa Izabel;

Salvador, Bahia, Brasil

\section{Introdução}

Os melanomas amelanóticos são caracterizados pela ausência de pigmento. ${ }^{1}$ É uma variante infrequente dos subtipos clínico-patológicos classicamente descritos, estimado entre 2 a $8 \%$ de todos os casos. ${ }^{1,2}$ Podem apresentar-se como mácula eritematosa em áreas fotoexpostas, com alterações epidérmicas, placa dérmica normocrômica, sem mudanças epidérmicas ou lesão pápulo-nodular. ${ }^{1}$ Sua apresentação mais comum é a variante nodular, entretanto, qualquer outra forma clínico-patológica pode ser encontrada. ${ }^{2}$ A dermatoscopia pode constituir uma ferramenta importante na suspeição desta entidade. ${ }^{2}$ Apesar de estarem ausentes as estruturas que sugerem a presença de melanina, é possível a visualização de padrões vasculares e pigmentação residual, não visíveis a olho nu. ${ }^{3} \mathrm{O}$ padrão vascular predominante nos melanomas amelanóticos e hipomelanóticos depende da espessura do tumor. ${ }^{2}$ Seu diagnóstico é dificultado, ainda, pela ausência de critérios bem estabelecidos. ${ }^{4}$ Por outro lado, não diferem dos melanomas pigmentados em termos de prognóstico ou terapêutica. ${ }^{1}$

\section{Relato de Caso}

Data Availability Statement: All relevant data are within the paper and its Supporting Information files.

Funding: This work was the result of authors' initiative. There was no support of research or publication funds.

Competing interests: The authors have declared that no competing interests exist.

\section{Copyright}

(C) 2020 by Santa Casa de Misericórdia da Bahia. All rights reserved.

ISSN: 2526-5563
Paciente, sexo masculino, 60 anos, portador de esquizofrenia, compareceu ao serviço de dermatologia, acompanhado de familiar que referiu surgimento de lesão na região lombar há tempo indeterminado, porém com aumento progressivo em 2 meses. Ao exame dermatológico, apresentava lesão tumoral de aproximadamente $4 \mathrm{~cm}$ de diâmetro, pedunculada, na região lombar, com área eritematosa peritumoral (Figura 1). Foi submetido à exérese, com margem de $2 \mathrm{~mm}$. O estudo anatomopatológico evidenciou extensa área de ulceração, recoberta por tampão fibrinoleucocitário. Na derme, observou-se Resumo do Artigo: Thadeu Santos Silva, Luciana Rebouças de Araujo, Gustavo Baptista de Almeida Faro. Nodular amelanotic melanoma. Letters. An. Bras. Dermatol. vol.94 no.4 Rio de Janeiro July/Aug. 2019 Epub Oct 17, 2019. https://doi.org/10.1590/abd18064841.20198453. 
Figura 1. Lesão no dorso do paciente.

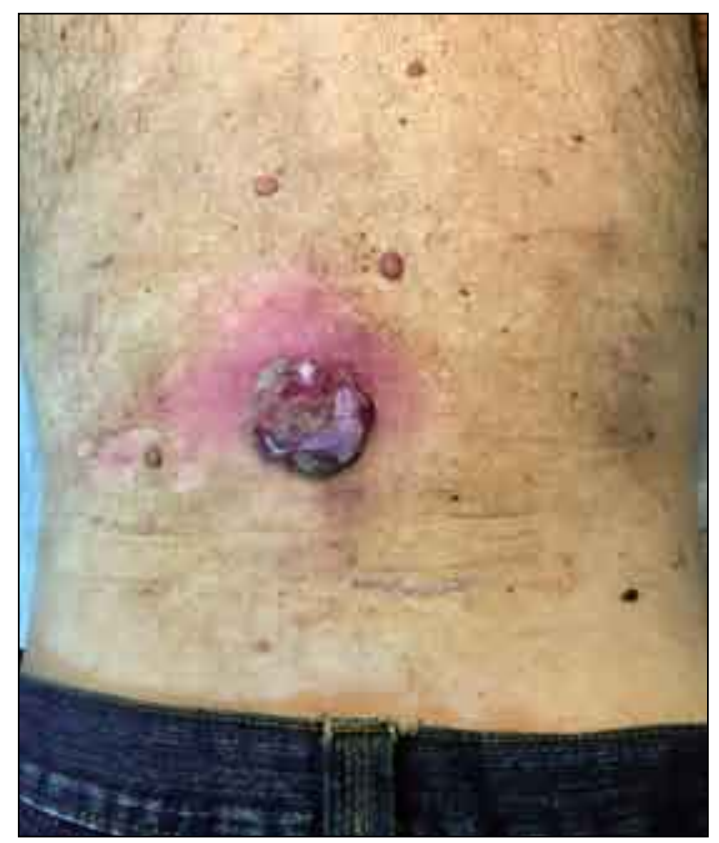

neoplasia maligna composta por células grandes, epitelioides e fusocelulares, formando blocos coesos e extensamente infiltrativos, além de áreas de necrose. As células exibiam intensa hipercromasia e pleomorfismo, com numerosas figuras de mitose típicas e atípicas, nucléolos evidentes e eosinofílicos e presença de pigmento acastanhado (Figura 2). O estudo imunohistoquímico revelou positividade para Melan A, S100, SOX10 e HMB45, confirmando o diagnóstico de melanoma maligno, tiponodular, com Breslow de $1,5 \mathrm{~cm}$ e índice mitótico de 15 mitoses/ $\mathrm{mm}^{2}$. Invasão linfática, sanguínea e perineural não foram detectadas. Margens cirúrgicas livres, distando 2,6mm da neoplasia.

Sendo a pigmentação um dos critérios norteadores do diagnóstico das lesões melanocíticas, a falta desta torna o melanoma amelanótico, muitas vezes, um desafio. ${ }^{1,2}$ A dermatoscopia é de grande importância para a avaliação dos tipos morfológicos das estruturas vasculares nestes casos. ${ }^{3} \mathrm{O}$ padrão vascular, sozinho, pode não ser suficiente, sendo essencial associar a clínica e a história do paciente. ${ }^{3}$ O diagnóstico definitivo só pode ser estabelecido histopatologicamente, sendo frequentemente necessário o estudo imunohistoquímico., ${ }^{2,4}$
Figura 2. Histopatologia. A. Ulceração. B: Células grandes, epitelioides e fusocelulares em blocos infiltrativos. C: Células com hipercromasia e figuras de mitose e pigmento acastanhado.

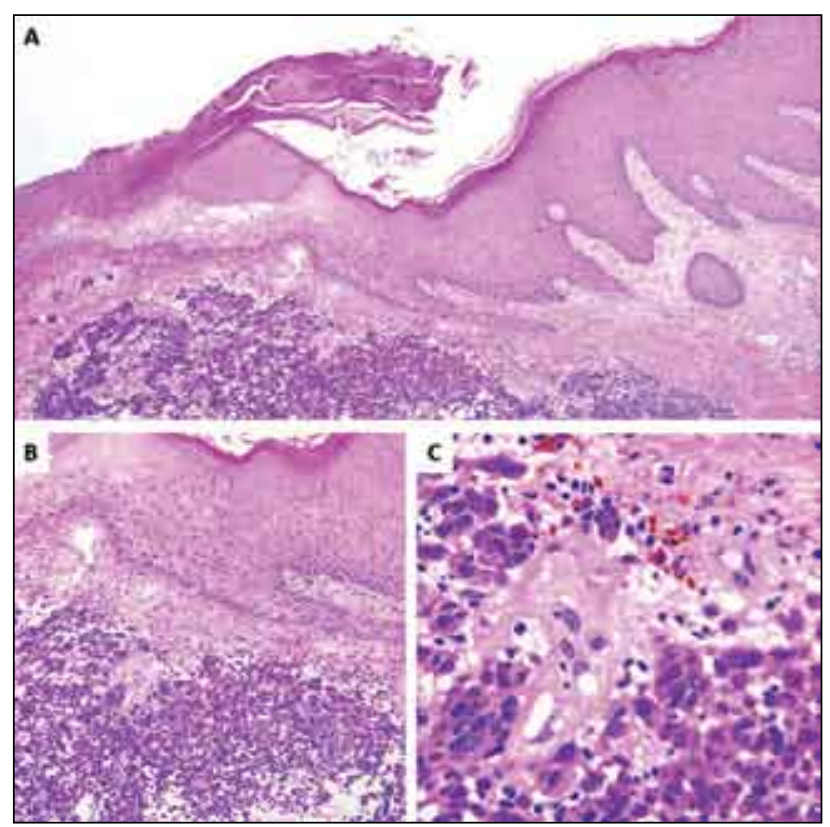

O presente relato evidencia a importância da histopatologia e imunohistoquímica para elucidação diagnóstica. A ausência de critérios definidos pode retardar a suspeição e diagnóstico, fundamentais na definição do prognóstico desta entidade altamente agressiva e potencialmente fatal. ${ }^{4}$

\section{Referências}

1. Thomas NE, Kricker A, Waxweiler WT et al. Genes, Environment, and Melanoma (GEM) Study Group. Comparison of clinicopathologic features and survival of histopathologically amelanotic and pigmented melanomas: a population-based study. JAMA Dermatol. 2014;150:1306-314.

2. Cheung WL, Patel RR, Leonard A, Firoz B, Meehan SA. Amelanotic melanoma: a detailed morphologic analysis with clinicopathologic correlation of 75 cases. J Cutan Pathol. 2012;39:33-9.

3. Jaimes N, Braun RP, Thomas L, Marghoob AA. Clinical and dermoscopic characteristics of amelanotic melanomas that are not of the nodular subtype. J Eur Acad Dermatol Venereol. 2012;26:591-6.

4. Mendes MS, Costa MC, Gomes CM, de Araújo LC, Takano GH. Amelanotic metastatic cutaneous melanoma. An Bras Dermatol. 2013;88:989-91. 